\title{
Liberdade para os índios no Império do Brasil. A revogação das guerras justas em 1831
}

Freedom for the Indians in the Brazilian

Empire. The 1831 revocation of "Just

War"

\section{Fernanda Sposito}

Doutoranda em História Social pela Universidade de São Paulo (FFLCH / USP - São Paulo / Brasil) e bolsista da Fundação de Amparo à Pesquisa do Estado de São Paulo (FAPESP) e-mail: fifaspo@yahoo.com.br

\section{Resumo}

Em 1831 foram revogadas as cartas régias de 1808 que permitiam fazer guerras justas contra os índios de São Paulo e Minas Gerais. Este artigo propõe analisar como se deu essa revogação, mostrando a relação entre os debates parlamentares realizados neste ano e as deliberações vindas da província de São Paulo. Com isso, vê-se que as relações conflituosas entre índios e paulistas nos sertões das vilas de Itapetininga e Itapeva nas primeiras décadas do Império tiveram repercussão no Parlamento, resultando, inclusive, na elaboração de um decreto imperial sobre o tema.

\section{Abstract \\ The royal decrees of 1808 that authorized a "Just War" against Indians in São Paulo and Minas Gerais were revoked in 1831. This article proposes to analyze how this revocation took place, showing the relationship between the Parliamentary debates during 1831 and the deliberations originating from São Paulo province. In this case, conflicts between the inhabitants of São Paulo and the Indians near the frontier towns of Itapetininga and Itapeva during the early nineteenth century had repercussions in the Parliament, ultimately resulting in the elaboration of an imperial decree on this issue. \\ Palavras-chave \\ legislação, debates parlamentares, indígenas, São Paulo \\ Keywords \\ legislation, parliamentary debates, Indigenous groups, São Paulo}

Este artigo, resultante da minha pesquisa de mestrado, é uma versão revista e ampliada do texto publicado nos Anais do Encontro Regional da ANPUH-SP em 2008, disponivel em CD e na rede (http://www.anpuhsp.org.br/downloads/ CD\%20XIX/PDF/Autores\%20e\%20Artigos/ Fernanda\%20Sposito.pdf; Último acesso em 16/01/2009). 
2

Os documentos que permitem acompanhar estes acontecimentos estão na coleção de manuscritos "Registro de Ofícios Diversos", do Arquivo do Estado de São Paulo (AESP), [citada a partir de agora como ROD-AESP], lata Itapetininga, C01054, anos 1822-1833, C-259, P-2, D-18 (20/07/1830). 0 desenrolar dos fatos estão nos documentos da sequência, até D-25 (16/09/1830); depois em D-37 (08/03/1831), D-57 e 57A (16/03/1832), D-61 (07/05/1832) e D-66 (21/06/1832).

3

Estes relatos podem ser acompanhados através do ROD-AESP: latas de Itapetininga, C01054, anos 1823-1833, Faxina, C012012, anos 18231838 e Guarapuava, C01025, anos 1824-1853.
Introdução

Em julho de 1830, há poucas léguas da vila de Itapetininga, no interior da província de São Paulo, 84 índios estão acampados pacificamente durante mais de uma semana. A respeito dessa reunião de índios, formada por homens, mulheres e crianças, acredita o juiz de paz da vila que eles estejam ali em busca da amizade dos moradores, já que estão instalados na entrada do sítio dos irmãos Paulino. Para manter o tom pacífico, apesar de ninguém na vila conseguir entender a fala dos indígenas, o juiz mandou distribuir-Ihes uma vara de tecido, projetando os frutos que se poderá obter para a civilização e a religião deste grupo, atraindo, inclusive, outros mais. No entanto, para que as coisas se deem desta forma, será imprescindivel que o Conselho da Província não se exima em reembolsar os gastos que deverão ser efetuados. 0 problema está, então, colocado, embora sua resolução, inclusive via ressarcimento de despesas, não seria algo tão imediato. ${ }^{2}$

Este evento destacado como ponto de partida para este artigo é um marco em relação a outros fatos ocorridos nas primeiras décadas do Império nos sertões da província paulista. Destoando de muitos acontecimentos anteriores, em que as autoridades locais invariavelmente escreviam ao centro da província alertando para o perigo que os índios causavam aos moradores do sertão, a partir deste ponto, os indígenas passam a ser descritos com maior benevolência, vistos como aliados possiveis e desejados. A região conhecida por sertões paulistas nesta época estende-se na direção oeste da província, além da vila de Sorocaba (4 $4^{\text {a }}$ comarca) até os limites com os países de origem hispânica, descendo a sudoeste a partir da vila de Curitiba (denominada comarca de Curitiba e depois de 1832, de 5 a comarca).

É bastante comum que os moradores que habitam essa região se refiram às populações indígenas com quem têm contato como um problema de difícil solução. Assim, das vilas de Itapeva, Itapetininga e da freguesia de Guarapuava ouvem-se queixas a respeito dos estragos causados por estes povos nas plantações e nas criações de animais dos moradores, bem como do risco de morte que correm em virtude destes conflitos. Constantemente pedem às autoridades provinciais munições para as expedições contra os indios, avisam que não podem se afastar de suas propriedades devido à possibilidade de perdê-las, ou dos seus familiares serem atingidos, solicitando às vezes de uma localidade à outra o envio de homens práticos nas expedições no sertão contra os índios. Neste momento estamos falando, portanto, de conflitos violentos, muitas vezes fatais, normalmente para os índios, que não dispõem de armas de fogo e são por elas aniquilados. ${ }^{3}$

Por isso, as descrições e os pedidos feitos pelos irmãos Paulino (Paulino Aires de Aguirra e Manuel Paulino Aires) e por algumas autoridades de Itapetininga dão-nos uma dimensão bem diversa do tipo de relação que se poderia, a partir de então, começar a se estabelecer com os indígenas. As mudanças de atitude, segundo se depreendem dos documentos paulistas, se dão em duas mãos. Ou seja, os antes ditos perigosos índios, agora são mais amigáveis. Eles vêm em paz, acompanhados de mulheres e crianças, o que demonstra não estarem em expedição de guerra, inclusive pedindo para serem acolhidos na fazenda. Ao longo dos próximos meses, os ajudantes Paulino contam os desdobramentos desse encontro, ao qual eles respondem de bom grado, mantendo os indígenas às custas de seus 
ROD-AESP, Itapetininga, C01054, anos 18231833 [C-259, P-2, D-23 (15/08/1830) e D-23A $(31 / 08 / 1830)]$.
5

Atas do Conselho da Presidência da Provincia de São Paulo, anos 1829-1832. Boletim, São Paulo, Departamento do Arquivo do Estado de São Paulo/Secretaria da Educação, vol.15 (nova fase), p.19-20, 1961.

6

Documentos interessantes para a História e Costumes de São Paulo. Vol. 86. Atas do Conselho da Presidência da Província de São Paulo, anos 1824-1829. São Paulo: Secretaria da Educação/ Arquivo do Estado, 1961. Sessão de 29/10/1828, p.172-173. A servidão temporária dos índios está estabelecida a partir da política joanina, que se dá com uma série de cartas régias a respeito dos chamados "botocudos" de Minas Gerais, autorizando-Ihes sua guerra justa. Em 05/11/1808 e 01/04/1809 passa a focalizar os "botocudos" dos campos gerais de Guarapuava e Curitiba. CUNHA, Manuela Carneiro da (org.). Legis/ação indigenista no século XIX. (1808-1889). São Paulo: EDUSP/Comissão Pró-İ́ndio, 1992. p.57-76.

7

Boletim, vol.15, Op. Cit. Sessão de 25/10/1830.

Sessões do Senado do Império em 03/11 e 11/11/1830 mencionam o pedido do Conselho da Província de São Paulo pelo fim da Carta Régia de D. João VI, apresentando um projeto sobre o mesmo. Anais do Senado do Império do Brazil. 1830. $3^{\circ}$ Tomo. $2^{\text {a }}$ sessão da $1^{2}$ legislatura. Rio de Janeiro: 1914. p.389-390; 448-449. [Anais do Senado do Imperio do Brazil, doravante ASIB] Este tema passa a ser discutido nas seguintes sessões de 1831: 13/05, 20/05, 25/05, 26/05, 07/06, 20/06, 21/06, sendo aprovado um segundo projeto, definido na sessão de 26/05/1831. (ASIB. 1831. $1^{\circ}$ Tomo. $1^{\text {a }}$ sessão da $2^{2}$ legislatura. Rio de Janeiro: 1914. p.106-114; 191-194; 204-210; 223; 244; 404-409). Em sessão de 05/05/1832. o Ministro da Guerra informa que o projeto pela revogação da carta régia foi sancionado pela Regência. ASIB. 1832. Tomo $1^{\circ}$. $1^{\text {a }}$ sessão da $2^{\mathrm{a}}$ legislatura (27 de Abril a 30 de Junho de 1832). Rio de Janeiro: 1914. p.11. recursos. 0 problema, segundo contam às autoridades, é que precisam ser ressarcidos dos gastos já feitos. Também pedem novas verbas oriundas do centro da província, visto que os indígenas já computam, poucos meses depois, o número de 65 indivíduos, indicando que a precariedade de condições tem sido fatal à sua sobrevivência. ${ }^{4}$ Ao longo do segundo semestre de 1830 até meados do ano seguinte, estes proprietários, bem como as autoridades locais, irão enfrentar as dificuldades de serem reembolsados pelos cofres provinciais nesta tentativa de abrigar um grupo indígena, padecendo também da falta de diretrizes e estruturas de tratamento dessas populações por parte do Império.

Ao mesmo tempo, as autoridades centrais da província paulista vêm apontando a necessidade de se repensar os conflitos com os índios para além do municiamento de tropas com pólvora e chumbo para combatê-los, como encaminha em novembro de 1829:

He do dever do Governo fazer aldear e Cathequizar esses Índios, que perseguidos pelos mais valentes e ferozes talvez procurão o nosso amparo, e não chegão a falla por não confiarem na nossa fé. (...) Ainda não temos Lei sobre este importante objecto, e ao Governo pertence dar as Instruções necessarias para se conseguir o fim. ${ }^{5}$

Essa ponderação é um passo importante no direcionamento de relações mais pacíficas com os índios, diferentemente do que fizera 0 Conselho da Presidência da Província um ano antes, ao deliberar sobre um destacamento militar que fora montado na mesma vila de Itapetininga. Naquele momento, Rafael Tobias de Aguiar, vice-presidente do Conselho, reitera a escravidão indígena, lembrando, no entanto, que se trata de uma condição temporária, devendo-se zelar pelo cumprimento dos 15 anos estabelecidos para a prestação de serviços dos índios. ${ }^{6}$

De qualquer forma, o que se nota é que a partir da década de 1830, o Conselho da Província de São Paulo, em consonância com os eventos ocorridos no sertão, passa a debater e propor ações sobre uma nova forma de tratamento dos índios. Isso culmina que, em outubro de 1830, três meses depois do aparecimento dos índios da fazenda dos irmãos Paulino, se funde uma Sociedade de Catequese e Civilização no âmbito da província paulista. ${ }^{7}$ Ainda que não se tenha muitas informações a respeito da atuação desta Sociedade, os princípios que norteiam a sua fundação e algumas de suas deliberações mostram que este novo tom, mais amistoso, de tratamento das populações indígenas também se encontra na mentalidade dos dirigentes provinciais.

Essa articulação entre os eventos do sertão e as medidas do Conselho da Província passa a ter, inclusive, um desdobramento maior: chega até o Parlamento brasileiro. Isso se dá quando, em novembro de 1830, entra na pauta do Senado um projeto que pede o fim das cartas régias de 1808 , que declaravam guerra justa contra os índios de São Paulo e Minas Gerais. 0 detalhe importante é que este projeto tem origem numa representação vinda de São Paulo, mostrando os maus tratos sofridos pelos índios, sua escravização perpétua, em vez de temporária, ao contrário, portanto, do que definiu, na letra da lei, a política joanina. Com isso, a Comissão de Colonização e Catequese do Senado federal, através do senador Visconde de Congonhas, influente político paulista, apresenta o projeto sobre o fim das guerras justas, que é lido nesta sessão e volta à pauta para ser discutido no ano seguinte, entre os meses de maio a junho. ${ }^{8}$ 
9

MONTEIRO, John Manuel. Entre o gabinete e o sertão. Projetos civilizatórios, inclusão e exclusão dos índios no Brasil imperial. In: Tupis, tapuias e historiadores: estudos de história indigena e indigenismo. Tese de livre docência. Instituto de Filosofia e Ciências Humanas da Universidade Estadual de Campinas, Campinas, 2001. p.129-169.

10

Ver: SPOSITO, Fernanda. Nem cidadãos, nem brasileiros. Indigenas na formação do Estado nacional brasileiro e conflitos na província de São Paulo. Dissertação (Mestrado em História Social). Faculdade de Filosofia, Letras e Ciências Humanas da Universidade de São Paulo, São Paulo, 2006. Cap. 1 e SLEMIAN, Andréa. 'Seriam todos cidadãos?' Os impasses na construção da cidadania nos primórdios do constitucionalismo no Brasil (1823-1824). In: JANCSÓ, István (org.) Independência: História e historiografia. São Paulo: Fapesp/Hucitec, 2005. p.829-847.

11

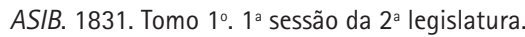
Rio de Janeiro: 1914. Sessão em 13/05/1831, p.106-107.
No âmbito do Parlamento brasileiro, este debate evidencia que 0 consenso a respeito do papel dos índios na nação brasileira seria algo impensável, já que as posições antagônicas sobre como proceder com relação aos indígenas têm sido a tônica ao longo da história secular dos conflitos entre estes dois mundos, até mesmo nos dias de hoje. Se, durante o período colonial, a legislação régia procurou estabelecer tanto as diretrizes ofensivas quanto assimiladoras no tratamento dos ameríndios, durante a formação do Estado brasileiro, o debate entre assimilação e extermínio também se estenderá, ainda mais na falta de uma diretriz geral, que só ocorrerá em $1845 .{ }^{9}$ Antes disso, como no caso a ser analisado aqui, as posições dos políticos e autoridades imperiais irão constantemente se confrontar, sem chegar a um consenso deliberativo, com exceção deste decreto realizado em 1831 para a revogação das guerras justas contra os indios. 0 que teria levado a este posicionamento é um dos aspectos que pretendo desenvolver aqui.

Antes disso, como introdução ao tema da política indigenista, cabe dizer que o pertencimento do indígena à nação brasileira é um ponto em aberto, eliminado a princípio pela Constituição de 1824, pois, assim como os escravos, eles não deviam participar da cidadania política nem civil debatida durante o projeto constitucional. ${ }^{10}$ No entanto, nenhuma proposta para este heterogêneo segmento populacional é aprovada, até porque se trata de uma questão que tem dimensões e sentidos diferentes nas várias partes que vão compor o Império do Brasil. Por isso, em 1831, quando se passa a discutir o fim da política de guerra justa contra os indios, estas pendências resvalam o tempo todo no debate. Como os indígenas não são reconhecidos legalmente como habitantes do Império, não havendo nenhu-ma orientação sobre como proceder, tanto na esfera cotidiana, quanto em relação às normas administrativas e legais, arbitrar sobre este aspecto é lidar sobre um tema bastante incômodo e controverso. 0 senador Almeida e Albuquerque, por exemplo, reflete uma preocupação muito repetida em diversos cantos do Império, a respeito da necessidade de se acabar com algumas políticas coloniais, como as guerras justas, dentro do Estado nacional em construção:

Eu acho, que será muito vergonhoso apparecer um acto Legislativo, em que se mostre ao mundo que temos sustentado uma guerra tão bárbara e que ainda no anno de 1831 se tratavam hostilmente os naturaes do Brazil. Portanto, não é uma medida Legislativa que cumpre tomar; o Governo é que deve punir os Presidentes e Magistrados que têm consentido nessa barbaridade execranda. ${ }^{11}$

Para este senador, pior do que a manutenção dessa prática em si, o problema é como se livrar de tal herança embaraçosa sem dar muita publicidade ao caso. 0 mais indicado neste caso, seria que o próprio Imperador (e neste caso, a Regência) executasse uma medida administrativa para se acabar com isso, em vez do Legislativo deliberar sobre o problema. Apesar desse temor, é mesmo do Senado que tal decreto surge, vencendo na própria casa parlamentar posturas que querem a manutenção da política ofensiva contra os índios. Como se verá com mais detalhes a seguir, para entender os motivos que levam à aprovação deste decreto, deve-se articular os níveis da prática política, do centro à província, chegando por sua vez, à dimensão local, em que os eventos para os quais as políticas são projetadas acontecem na prática cotidiana. Esse aspecto, por sua vez, nos 
Os relatos coevos apresentam um quadro bastante interessante da economia e da sociedade paulista nas primeiras décadas do século XIX: SAINT-HILAIRE, Auguste de. Viagem à Província de São Paulo. Belo Horizonte/São Paulo: Itatiaia/ Ed. USP, 1976; SPIX, Johann B. e MARTIUS, Karl Friedrich Von. Viagem pelo Brasil: 1817-1820. Vol. I. 4a ed. Belo Horizonte/São Paulo: Itataia/Ed. USP, 1981 e MULLER, Daniel Pedro. Ensaio d'um quadro estatistico da Provincia de S. Paulo. São Paulo: Reedição literal. Secção de Obras d' "0 Estado de São Paulo", 1923 [1838].

13

Na década de 1830, essa região está circunscrita à $5^{a}$ comarca, cujas cabeças de termo são as vilas de Curitiba e Paranaguá e em 1853 será desmembrada para compor a nova província do Paraná.

14

As cartas régias que declaram guerras aos índios "botocudos" de Minas e São Paulo são editadas em 13/05/1808, 24/08/1808, 05/11/1808, 02/12/1808, 01/04/1809. In: CUNHA, Manuela Carneiro da (org.). Legislação indigenista..., 0p. Cit., p.57-72.

15

Uma análise sobre esse processo do período colonial pode ser visto em TAUNAY, Affonso de Escragnolle. História Geral das Bandeiras Paulistas. Tomos II e III. São Paulo: Typographia Ideal/H. L. Canton, 1926-1927 e MONTEIRO, John Manuel. Negros da terra. Índios e bandeirantes nas origens de São Paulo. São Paulo: Companhia das Letras, 2000. 16

Sobre 0 avanço das atividades econômicas para as terras indígenas do sul e sudoeste do pais no final do século XIX ver LEITE, Rosângela Ferreira. Nos limites da colonização. Ocupação territorial, organização econômica e populações livres pobres. (Guarapuava, 1808-1877). Tese (Doutorado em História Econômica). Faculdade de Filosofia, Letras e Ciências Humanas da Universidade de São Paulo, São Paulo, 2006; AMOROSO, Marta Rosa. Catequese e evasão. Etnografia do aldeamento indígena de São Pedro de Alcântara, Paraná (1855-1895). Tese (Doutorado em Antropologia Social). Faculdade de Filosofia, Letras e Ciências Humanas da Universidade de São Paulo, São Paulo, 1998; CORREA, Dora Shellard. Paisagens sobrepostas. Índios, posseiros e fazendeiros nas matas de Itapeva (1723-1930). Tese (Doutorado em História Econômica). Faculdade de Filosofia, Letras e Ciências Humanas da Universidade de São Paulo, São Paulo, 1997; GAGLIARDI, José Mauro. O indígena e a República. São Paulo: Hucitec/Ed. USP/Secretaria do Estado da Cultura, 1989; CREDDO, Maria do Carmo Sampaio di. A propriedade da terra no Vale do Paranapanema. A Fazenda Taquaral (1850-1910). Tese (Doutorado em História). Faculdade de Filosofia, Letras e Ciências Humanas da Universidade de São Paulo, São Paulo, 1987. 2 vols.; LIMA, João Francisco Tiddei. A ocupação da terra e a destruição dos índios na região de Bauru. Dissertação (Mestrado em História). Faculdade de Filosofia, Letras e Ciências Humanas da Universidade de São Paulo, São Paulo, 1978; WITTMANN, Luisa Tombini. $O$ vapor e o botoque: imigrantes alemães e índios Xokleng no Vale do Itajai/SC (1850-1926). Florianópolis: Letras Contemporâneas, 2007.

17

BELLOTTO, Heloísa Liberalli. Autoridade e conflito no Brasil colonial: o governo de Morgado de coloca de frente com as populações indígenas do interior de São Paulo, procurando mostrar também suas posturas políticas com relação aos invasores de suas terras.

\section{Disputas no sertão}

0 território da capitania de São Paulo, depois alçado à condição de província na nova configuração do Império português nos primeiros anos do século XIX, abriga regiões de características demográficas e econômicas bastante diversas. As lavouras nas vilas e cidades que se expandiram para além da capital paulista, tanto no sentido oeste, quanto em direção à corte carioca, consolidam-se como uma economia de mercado em franca ascensão, representadas, respectivamente, pelas lavouras canavieiras do Oeste novo (Campinas, Itu, Piracicaba etc.) e pela cafeicultura do Vale Paraíba. Já o sertão ainda inspira receios por parte dos moradores e proprietários que ali vivem, bem como das autoridades centrais da província. ${ }^{12}$ Com relação a essas áreas de contorno e controle inalcançáveis, tanto esses temores são procedentes que eles recebem uma atenção especial da administração real, no mesmo ano de sua chegada às terras americanas, em 1808. Para essa região ${ }^{13}$, o príncipe-regente D. João entende que sua ocupação seria assegurada com uma política ofensiva contra as populações nativas, escravizando-as ou matando-as, através das guerras justas, como já havia decretado alguns meses antes para o sertão de Minas Gerais. ${ }^{14}$

No caso paulista, as tentativas e intenções de ocupar com as populações de origem europeia as terras à oeste de Curitiba falharam durante boa parte do período colonial. Desde a destruição das aldeias jesuíticas espanholas na região do Paraná e Guairá, ainda no século XVII, a queda demográfica dos nativos e a transferência das reduções para o sul, no Uruguai e Tape, tornaram essa área um amplo espaço onde os indígenas remanescentes ou aquelas etnias não atingidas pelas invasões ibéricas podiam manter-se a salvo. ${ }^{15}$ Essas terras continuarão sendo identificadas na segunda metade do Oitocentos como "terra de bugres", ou "sertão desconhecido", conforme mapa feito por Cândido Mendes em 1868. Ainda nesta época, este sertão indômito corresponderá a uma parte equivalente ou maior às porções da província que serão conhecidas e dominadas pelo Estado brasileiro e seus cidadãos. A ocupação definitiva dos extremos pelos grupos brasileiros será um projeto levado a cabo já na definitiva expansão da cafeicultura e das ferrovias em direção ao Paraná, Rio Grande do Sul, Santa Catarina e Mato Grosso, processo de conflitos com as populações indígenas que adentrará mesmo o século XX. ${ }^{16}$

Isso porque, ainda na segunda metade do século XVIII, a política de definição das fronteiras com o Império espanhol, empreendida pelo marquês de Pombal (1750-1777), não conseguiu efetivar a ocupação pelos luso-brasileiros no extremo-oeste paulista, tal como intentado pelo capitão-general de São Paulo, Morgado de Mateus (1765-1775), em expedições aos rios Iguatemi e Tibagi. ${ }^{17}$ Foi fundada uma série de vilas em decorrência dessa política expansionista, que se tornam palco dos conflitos com indígenas nas primeiras décadas do XIX. Os locais onde mais diretamente se registram conflitos com essas populações no período em questão são as vilas de Itapeva (também chamada Faxina), fundada em 1769 e em Itapetininga, de 1770 , ambas na $4^{a}$ comarca. Com relação à $5^{a}$ comarca, o ponto mais extremo é a vila de Castro, fundada em $1788 .^{18}$ Nesta vila, depois de muitas tentativas de se instalarem fazendas de criação de gado, 
Mateus em São Paulo. São Paulo: Secretaria do Estado da Cultura, 1979.

18

MULLER, Daniel Pedro. Ensaio d'um quadro estatístico..., Op. Cit.

19

LEITE, Rosângela Ferreira. Nos limites da colonização..., Op. Cit. e SALLAS, Ana Luisa Fayet. Os povos indigenas dos Campos de Guarapuava. Séculos XVIII-XIX. In:___ (org.). Documentação sobre os povos indígenas. Séculos XVIII e XIX. Curitiba: Aos Quatro Ventos, 2000. p.1-25.

20

LIMA, Francisco das Chagas. Memória sobre o descobrimento e colonia de Guarapuava In: SALLAS, Ana Luisa Fayet (org.). Op. Cit., p.55-80. TOMMASINO, Kimiye. A história dos Kaingáng da Bacia do Tibagi: Uma sociedade Jê meridional em movimento. Tese (Doutorado em Antropologia). Faculdade de Filosofia, Letras e Ciências Humanas da Universidade de São Paulo, São Paulo, 1995.

21

Para acompanhar esses fatos ver ROD-AESP: Guarapuava (lata C01025, anos 1824-1853) e as atas publicadas do Conselho Geral da Província (Documentos interessantes para a história e os costumes de São Paulo. Vol. 86. 0p. Cit. e Boletim. Vol. 15. Op. cit.) e da Assembleia Provincial de São Paulo (Annaes da Assembléa Legislativa Provincial de S. Paulo. 1835-. São Paulo: Typographia Piratininga/Secção de Obras d' "O Estado de São Paulo", 1923-).

22

ROD-AESP: Faxina, C01012, anos 18231838 [C-217, P-1, D-2 (20/03/1823), D-10A e D-12 (24/01/1824), D-22B (20/05/1825), D-51A, 51B, 51C, 51D, 51E (20 a 26/09/1826), D-35 (03/02/1827), D-41 (14/05/1827), D-51 $(19 / 01 / 1828)]$

23

ROD-AESP: Itapetininga, C01054, anos 18231833 [C-259, P-1, D-65, D-65A, D-65B, D-66 (19/06 a 08/08/1826)] Faxina, C01012, anos 1823-1838 [C-217, P-1, D-30 (17/07/1826) e D-33 (08/10/1826)].

24

ROD-AESP: Itu, C01068, anos 1829-1834 (C-272, P-2, D-74, s.d)

25

Documentos interessantes para a história e costumes de São Paulo. Vol. 86. Op. Cit., p.19.

26

13/05/1808. Carta Régia ao Governador e Capitão General da capitania de Minas Gerais sobre a guerra aos Indios Botecudos". In: CUNHA, Manuela Carneiro da (org.). Legis/ação indigenista..., 0p. Cit., p.57-60. bem como fixar uma rota de passagem para o mercado abastecedor das tropas e dos animais do sul, oriundos da província de Rio Grande, instalase em 1810 a povoação de Atalaia, na região de Guarapuava. Em 1819 é fundada a poucas léguas dali a freguesia e aldeamento Nossa Senhora do Belém do Guarapuava. ${ }^{19}$ Território das etnias kaingang e xokleng, as instalações na região participam das disputas interétnicas destes grupos jê meridionais que, se dividindo em duas metades opostas, inimigas e complementares (como os votorons e os camés, por exemplo) ${ }^{20}$, ora se aliam aos paulistas para se proteger dos seus antigos inimigos, ora usam as vantagens táticas dessa aliança para atacar aqueles grupos que não estão aldeados, conforme relatos do missionário Francisco das Chagas Lima e dos capitães que ali atuam.

A região de Guarapuava é ponta de lança na ocupação do sertão e a instabilidade de suas povoações, no que tange à presença indígena e à resistência dessas populações em manter-se sob controle dos moradores e das autoridades paulistas, é constantemente referida. Isso pode ser verificado ao se analisar alguns documentos pertencentes aos dirigentes desta freguesia, ou acompanhar as atas do Conselho da Província de São Paulo, e depois, da Assembleia Provincial de São Paulo, a partir de $1835 .{ }^{21}$ Com relação às vilas de Itapeva e Itapetininga, a primeira também tem um papel de proeminência nos conflitos com os índios, visto que nos extremos da vila, especialmente no bairro do Guareí, os moradores montam constantemente expedições para atacar os nativos da região. ${ }^{22}$ Inclusive os habitantes de Itapetininga, quando os ataques contra os indígenas nesta vila se tornam mais frequentes, pedem auxílio aos homens "práticos" nas guerras do sertão que residem em Itapeva. ${ }^{23}$

Neste contexto, os moradores dos sertões paulistas usam das prerrogativas das guerras justas de D. João, obtendo direito de ocupar as terras que conquistassem e podendo aprisionar os indígenas por 15 anos, para Ihes prestarem serviços, caso estes povos não aceitassem pacificamente o comando das armas reais. Esses incentivos são lembrados invariavelmente tanto pelos moradores destas regiões como pelas autoridades provinciais. Os primeiros para poderem se garantir da posse daqueles "bugres" que aprisionam em expedições do sertão. Pois até no centro açucareiro da província, a vila de Itu, se encontram no início da década de 1830 cinco indigenas cativos oriundos "das matas", tendo sido comprados por cerca de 50 mil réis cada um. ${ }^{24}$ Já as autoridades provinciais, por sua vez, para oferecerem vantagens àqueles que fossem em nome do Império empreender atividades de exploração nas regiões distantes, a exemplo da construção da Estrada da Mata no sul em 1824, reiteram que os soldados e fazendeiros que para lá fossem teriam os mesmos benefícios assegurados pelas cartas régias de $1808 .^{25}$

A carta régia de 13 de Maio de 1808, referente especialmente a Minas Gerais, é a primeira da sequência que autoriza as escravizações e matanças dos índios ao longo dos próximos anos. Neste específico texto legal, a coroa decide que os meios cordiais para trazerem os indígenas à civilização não fazem efeito, portanto ficam autorizadas guerras contra estes inimigos, sendo distribuídos terrenos àqueles que se engajarem no Corpo de Soldados Pedestres, bem como podem tornar-se prisioneiros de guerra por dez anos, sob cuidados do comandante, todos aqueles "bárbaros" que estejam em luta contra os soldados. ${ }^{26} \mathrm{~A}$ carta régia de dois de dezembro de 1808, por sua vez, considera como devolutos (ou seja, sob posse da 
"02/12/1808. Carta Régia. Sobre a civilisação dos Indios, a sua educação religiosa, navegação dos rios e cultura dos terrenos". In: CUNHA, Manuela Carneiro da (org.). Legislação indigenista..., 0p. Cit., p.66-69.

28

"05/11/1808. Carta Régia. Sobre os indios Botocudos, cultura e povoação dos campos geraes de Coritiba e Guarapuava". In: CUNHA, Manuela Carneiro da (org.). Legislação indigenista..., 0p. Cit., p.62-64.

29

"01/04/1809. Carta Régia. Approva o plano de povoar os Campos de Guarapuava e de civilisar os indios bárbaros que infestem aquelle territorio".In: CUNHA, Manuela Carneiro da (org.). Legislação indigenista..., 0p. Cit., p.69-72.

30

"05/09/1811. Carta Régia approva o plano de uma Sociedade de comercio entre as Capitanias de Goyas e Pará e concede isenções e privilegios em favor da mesma sociedade".In: CUNHA, Manuela Carneiro da (org.). Legis/ação indigenista..., 0p. Cit., p.63.

31

SAINT-HILAIRE, Auguste de. Viagem à Província de São Paulo. Op. Cit. e ROD-AESP, Faxina: C01012, anos 1823-1838 e C01013, anos 18241853.

32

$80^{a}$ sessão ordinária em 04/10/1828. Documentos interessantes para a história e costumes de São Paulo. Vol. 86. Op. Cit., p.150151.

33

Evidências de grupos indígenas que vêm em busca de alianças com os paulistas: em Itapetininga são os documentos referentes aos irmãos Paulino, citados na nota 2. Em Itapeva, ver ROD-AESP, Faxina, C01012, anos 18231838 [C-217, P-2, D-55 (08/03/1832), D-48 (28/03/1832), D-64 (26/11/1832)].

34

Para dados etnográficos a respeito dos kaingangs, IHERING, Hermann von. Os Guayanãs e Caingangs de São Paulo In: Revista do Museu Paulista, São Paulo, vol.6, Typographia do "Diario Official", p.23-62, 1904; MONTEIRO, John Manuel. Tupis, tapuias e a história de São Paulo. Revisitando a velha questão guaianá. In: Novos Estudos-CEBRAP, São Paulo, n.34, p.125 135, novembro de 1992; TOMMASINO, Kimiye. A história dos Kaingáng da Bacia do Tibagi... Op. Cit.; AMOROSO, Marta Rosa. Catequese e evasão..., Op. Cit. coroa) todos os terrenos resgatados das incursões dos índios "botocudos", ou aqueles dados em sesmarias que não foram demarcados ou cultivados nos locais em que as expedições estão atuando em Minas Gerais. ${ }^{27}$ Para 0 caso de São Paulo, reclamando das condições de sobrevivência nos campos gerais de Curitiba e Guarapuava e na estrada que vai da vila de Faxina (Itapeva) à vila de Lages, em Santa Catarina, o príncipe-regente declara guerra contra os chamados "bugres" da região, devendo-se montar corpos militares para a expedição, podendo cada morador que "segurar" um dos índios, fazê-lo seu prisioneiro de guerra por 15 anos, usando-o para o serviço que quiser. ${ }^{28} \mathrm{Em}$ abril do ano seguinte, D. João detalha melhor como fazer a ocupação desses novos campos, pedindo melhores modos no tratamento aos indios, para que eles se convençam dos beneficios de serem recolhidos junto aos representantes reais. No entanto, a escravização, através da prestação de serviços por 15 anos dos prisioneiros de guerra não só é reafirmada, como se prevê que estes escravos possam ser vendidos. ${ }^{29}$

Cabe aqui um aparte, que se refere ao fato de terem sido estendidos estes "privilégios" dados aos exploradores de Minas em 13/05/1808 também àqueles que estavam estabelecendo uma companhia de comércio entre as capitanias do Pará e Goiás, conforme medida tomada por D. João em $1811 .^{30}$ Excetuando-se este sucinto documento, a extensão das cartas régias às demais regiões do Império português não é oficializada legalmente. Porém, se julgarmos que o espírito dessas medidas tenha prevalecido, é bastante provável que tenha sido uma prática generalizada nas regiões de conflito com as populações indígenas, ainda que a posse real dos índios como escravos não seja reconhecida pela coroa nas outras regiões não especificadas.

Por sua vez, no caso de São Paulo, essas medidas são reiteradas na prática cotidiana dos moradores dos sertões, conforme alguns eventos descritos acima. Assim, atacar indígenas, escravizá-los, ou mesmo vender as "peças aprisionadas" fazem parte de uma economia periférica, marcada pelas criações de gado, pelas fazendas para pouso de tropeiros e animais situadas no caminho do sul a Sorocaba, cujas instalações precárias tanto horror causam ao viajante Saint-Hilaire em seu itinerário pela província na época. ${ }^{31}$ Mas, em meados dos anos 30, o trato para com os indígenas passa a ser concebido e efetuado de uma maneira diferente, o que é expresso tanto nas indicações do Conselho da Província, como nas atitudes dos moradores do sertão. 0 presidente do Conselho em 1828, depois de constatar que as tentativas de civilização em Guarapuava não têm surtido o efeito desejado e que não vingou a iniciativa de trazer estes índios para trabalharem na construção da Estrada de Cubatão, conclui que os índios não são nem bons nem maus, mas meros autômatos, aos quais cumpre educar e ensinar. Para isso, ele mesmo manda conduzir à capital paulista dois nativos de 14 anos, pagando a instrução deles. ${ }^{32}$

No nível local, com o evento na fazenda dos Paulino, passa-se a buscar acolher grupos indígenas, que vêm em grande número, na esperança de serem alojados pelos moradores, a fim de não serem escravizados. ${ }^{33}$ Como normalmente se faz virem índios de Itapeva para servirem como "línguas" (tradutores) daqueles que chegam em Itapetininga, pode-se perceber que se tratam de grupos do mesmo tronco linguístico e isso elimina, portanto, as etnias presentes em Guarapuava, os kaingangs e xoklengs, também denominados guaianás ou guaianãs, que são do tronco macro-jê. ${ }^{34} 0 \mathrm{~s}$ que aparecem nas vilas da $4^{a}$ comarca, seguindo algumas descrições que 
35

Sobre os povos de origem guarani, como os kaiowás ver: OLIVEIRA, José Joaquim Machado de. A emigração dos Cayuaz. Narração coordenada sob apontamentos dados pelo Sr. João Henrique Elliot pelo socio effetivo o sr. Brigadeiro [...]. In: Revista do Instituto Historico e Geographico do Brazil, Rio de Janeiro, tomo 19, Typographia Universal Laemmert, p.434-447, 1856; SCHADEN, Egon. Os primitivos habitantes do território paulista. In: Revista de História, 8, n.18, p.385-406, 1954; MOTA, Lúcio Tadeu. Relações interculturais na bacia dos rios Paranapanema/ Tibagi no século XIX. Apresentado no XXIII Simpósio Nacional de História, ANPUH. Londrina: 2005 (disponivel no sítio: www.ifch.unicamp.br/ inb ) e AMOROSO, Marta Rosa. Op. Cit.

36

Pedro Puntoni analisa a dicotomia tupi-tapuia em PUNTONI, Pedro. A Guerra dos Bárbaros. Povos indígenas e a colonização do sertão nordeste do Brasil (1650-1720). São Paulo: Hucitec/ Edusp, 2002. Sobre esta questão em São Paulo, ver MONTEIRO, John Manuel. Tupis, tapuias e a história de São Paulo..., Op. Cit.

37

ROD-AESP, Iguape, C01039, anos 18321838 [C-244, P-2, D-23 (10/03/1835), D-26 (20/03/1835), D-30 (07/05/1835), D-32 (27/05/1835), D-42 (14/07/1835), D-42A (15/07/1835), D-44A (10/08/1835)] Sobre a vinda de índios a Iguape em 1843: ROD-AESP, Iguape, C01040, anos 1839-1843 [C-245, P-3, D-84 (12/09/1843)].

38

ROD-AESP, Itapetininga [C-259, P-2, D-23 (15/08/1830)]. podemos inferir como dados etnográficos, têm alguns tipos de hábitos bem particulares: perfuração do lábio inferior, o que faz com que sejam chamados de "botocudos", além do fato de trazerem mel e mantas tecidas para estabelecerem alianças com os "brancos". Isso os aproxima dos hábitos dos povos do tronco tupi-guarani, que habitam essa região à época, como as etnias guarani e kaiowá (também grafados, à época como "caiuás" ou "cayuãs"). Este último grupo parece se encaixar mais nas descrições, uma vez que usa o tembetá, enfeite cilíndrico de resina, perfurando abaixo do lábio inferior. ${ }^{35}$ Inclusive numa sequência dos eventos, a partir da década de 1840, estes "caiuás" ou "botocudos" serão considerados como guarda avançada a favor da "civilização" e da ocupação do sertão pelos paulistas contra os chamados "selvagens guaianãs", retomando, assim, a clássica oposição esquemática tupi-tapuia, tão presente na colonização da América nos séculos anteriores. ${ }^{36}$

Com isso, percebe-se que a diversidade étnica dos povos indígenas, as relações pré-existentes entre os grupos do oeste paulista, em suas disputas territoriais e guerras intertribais são instrumentalizadas pelos agentes do Império brasileiro a favor de seus intentos de dominação e ocupação dessas terras e povos. Aqui interessa particularmente a procura dos grupos kaiowás por uma aliança menos danosa com os moradores dos arredores das vilas de Itapeva, Itapetininga e também na vila litorânea de Iguape ( $6^{\mathrm{a}}$ comarca), que faz divisa com Itapetinga e Itapeva. Nesta parte do litoral sul paulista, os registros da presença de grupos indígenas datam de 1835 e 1843. Estes índios provavelmente também são kaiowás, pois se pede que venha "língua" presente entre aqueles que estão alojados na $4^{\text {a }}$ comarca para ajudar no contato e "pacificação" dos recém chegados em Iguape. ${ }^{37}$ É interessante perceber que o principal argumento dos índios que vêm a estas vilas normalmente em grande número pedindo para serem acolhidos nas fazendas, é que pretendem com isso evitar a escravidão e maus tratos. Isso indica que a relação entre esses povos não era recente e que eles procuram se colocar nessa relação, a partir de então, de uma maneira que thes custassem menos mortes e sacrifícios. Um dos pontos altos desse processo é que parece que tal estratégia surte efeito, já que os legisladores do Império, atendendo ao parecer dos dirigentes da província de São Paulo, resolvem revogar as guerras justas contra os índios daquela região, depois de quase uma década do início da construção do Estado brasileiro, o que evidencia seu silêncio e omissão a respeito do tema.

Por fim, ainda sobre a província paulista, cabe dizer que os irmãos Paulino alojam o grupo que lá aparece, gastam com o sustento, alimentação e plantações para os índios e, apesar de mandarem várias tabelas com o total despendido com o grupo, aparentemente não são ressarcidos. Em 15 de Agosto de 1830, 30 dias após a instalação dos índios em sua fazen$d a$, os Paulino avisam: "nos oferecemos para continuar com o tratamento a estes individuos nestes primeiros annos, edificando aranxamento e rossas nas nossas terras gratuitamente por estes dous annos, com tanto que sejamos saptifeito das dispezas feita e as q. se ouver de fazer". ${ }^{38} \mathrm{Na}$ lógica dos paulistas dos sertões, eles não precisam receber soldo por "civilizar" os indios, mas os gastos efetuados com essa população obviamente devem ser bancados pelos cofres públicos. Ao mesmo tempo, esse tratamento dos indígenas está longe de ser caridoso: os fazendeiros estavam obtendo mão de obra acessivel e gratuita para suas atividades produtivas, sob pretexto de estarem "acolhendo" os índios. Tanto é assim que nas próximas semanas 
39

ROD-AESP, Itapetininga [C-259, P-2, D-23-A $(31 / 08 / 1830)]$.

40

Uma lista com as despesas dos Paulino é mandada no meio de agosto de 1830. ROD-AESP, Itapetininga [C-259, P-2, D-23'B (19/08/1830)].

41

Boletim, Vol.15. Op. Cit. Sessão de 05/01/1832, p.203-204.

42

Os trabalhos de Iris Kantor [KANTOR, Iris. Esquecidos e renascidos. Historiografia acadêmica luso-americana (1724-1759). São Paulo/Salvador: Hucitec/Centro de Estudos Baianos/UFBA, 2004] e de Ana Paula Medicci [MEDICCl, Ana Paula. Entre a "decadência" e o "florescimento": a capitania de São Paulo na interpretação de memorialistas e autoridades públicas (17821822). Dissertação (Mestrado em História Social). Faculdade de Filosofia, Letras e Ciências Humanas da Universidade de São Paulo, São Paulo, 2005] discutem as propostas e os anseios que intelectuais, politicos e autoridades tinham a respeito das populações indigenas a partir da segunda metade do século XVIII no contexto do Diretório pombalino e após a sua derrocada em 1798.

43

Sobre as Cortes de Lisboa, BERBEL, Márcia Regina. A nação como artefato. Deputados do Brasil nas Cortes portuguesas (1821-1822). São Paulo: Hucitec, 1997. Sobre a questão indígena nas Cortes: BOHER, George. Some brazilian proposals to the Cortes Gerais, 1821-1823, on the indian problem. In: Actas do $3^{\circ}$ Colóquio Internacional de Estudos Luso-Brasileiros. Vol. 2. Lisboa: 1960. p.201-209 e MOREIRA NETO, Carlos Araújo de. A política indigenista brasileira durante o século XIX. Tese (Doutorado em Antropologia). Rio Claro: Universidade Federal de São Carlos, 1967. p.345-354. avisam que os gastos já totalizados são da ordem de 400 mil réis, mas que em virtude da decadência das rendas provinciais, os Paulino se eximem de receber o ressarcimento. No entanto, necessitam de um conto de réis para as instalações que hão de fazer ali a partir de então, para o bem dos índios. ${ }^{39}$ Esse caráter dito benéfico aos índios pode ser relativizado quando se nota a contratação de camaradas para a guarda dos "bugres", mostrando que a acomodação na fazenda dos Paulino se faz também através da coerção, até porque se trata de colocar os índios para trabalharem na terra. ${ }^{40}$

No que se refere ao apoio dos dirigentes provinciais para estes fazendeiros, nada de muito concreto se estabelece no nível imediato, ainda que tenha sido fundada a Sociedade para Catequese e Civilização dos Índios da província, em outubro de 1830. Isso porque, até janeiro de 1832, o Conselho da Província ainda não terá ressarcido os Paulino dos 400 mil réis gastos, nem os reembolsado dos demais gastos efetuados nos últimos anos. Embora tenham recebido algumas planilhas de custos, alegam que não podem liberar a verba sem uma nova descrição pormenorizada dos tipos de gastos efetuados, acompanhada da relação dos índios que presentemente estão lá. ${ }^{41}$ Portanto, ainda que os dirigentes apoiem tal prática no discurso, na realidade não envidam muitos esforços para acelerá-lo e, nesse sentido, a função da Sociedade criada no calor dos acontecimentos, perde sua operacionalidade. De toda forma, não deixam de ser ouvidos no Parlamento brasileiro, fazendo com que os ecos do sertão fossem ali ressoados.

\section{Repercussões no centro do Império}

Para situar o impacto da revogação das cartas régias é preciso enxergar o sentido da política indigenista na primeira metade do século XIX a partir de dois aspectos. De um lado, compreender que, ainda que as intenções presentes à época não vigorem, isso não significa que não haja projetos para os indígenas e que sua exclusão do corpo da lei represente necessariamente sua inexistência real ou simbólica na construção do Estado nacional brasileiro. Ao mesmo tempo, essa presença e importância das populações indígenas no século XIX nos diferentes recônditos do Império se fazem ouvir através dos relatos locais, os quais, por sua vez, pressionam a estrutura burocrática e legal a responder às demandas. Isso coloca a questão de que política, no que interessa a esse estudo, não significa apenas aquilo que está no corpo da lei, mas as práticas efetuadas nos diversos âmbitos da vida cotidiana e pública da sociedade que, de uma maneira ou outra, repercutem na elaboração legislativa.

Assim, desde o fim do Diretório pombalino, diversas autoridades, proprietários e políticos passam a elaborar memórias, reflexões e projetos que visam pensar a questão que a colonização havia deixado em aberto: o que fazer com as populações indígenas? ${ }^{42}$ Essa necessidade se apresenta invariavelmente quando se tentam equacionar os impasses do Império colonial em crise, expresso nas Cortes de Lisboa em 1821, e decididamente após a ruptura com Lisboa, durante a Assembleia Constituinte brasileira em 1823. Nas Cortes de Lisboa, dentro de uma tentativa mais radical de modernizar as estruturas do Antigo Regime, àquela altura nitidamente em frangalhos, aparecem alguns projetos do Brasil a respeito do que fazer com as populações indigenas existentes no Império. ${ }^{43}$ Ainda que alguns deputados das partes do Brasil fossem gradualmente abandonando as Cortes e começassem a gestar uma proposta alternativa, que resultou na ruptura com Portugal e na construção de outro modelo de Estado, algumas das ideias surgidas no 
44

SILVA, José Bonifácio de Andrada e. Apontamentos para a civilização dos indios bravos do Imperio do Brazil. In: CUNHA, Manuela Carneiro da (org.). Legislação indigenista..., Op. Cit., p.347-360

45

Os autores de propostas sobre os índios nas Cortes de Lisboa são, além de Bonifácio: José Caetano Ribeiro da Cunha e Francisco Ricardo Zany (ambos do Pará), Domingos Borges de Barros (da Bahia) e Francisco Muniz de Tavares (de Pernambuco). 0 texto de Zany, como foi encaminhado para discussão, está publicado em "Projeto para os índios do Grão Pará. Sessão de 26 de agosto de 1822". In: Diário das Cortes. 1821-1822. Cópia da Biblioteca Nacional de Lisboa.

46

Annaes do Parlamento Brazileiro. Assembléa Constituinte, 1823. Tomo II. Rio de Janeiro: Typographia Parlamentar, 1877. Sessão em 18/06/1823, p.97.

47

Segundo o art. 245 do projeto de Constituição, tem-se: "Terá igualmente cuidado de criar estabelecimentos para a catequese e civilização dos índios, emancipação lenta dos negros e sua educação religiosa e industrial". "Doc. 316-2. Projeto de Constituição para o Império do Brasil (Projeto Antonio Carlos), elaborado pela Comissão da Assembléia Geral Constituinte e Legislativa (30 de setembro de 1823)". In: BONAVIDES, Paulo e AMARAL, Roberto (orgs.). Textos políticos da História do Brasil. Vol. 8. 3aed. Brasília: Senado Federal, 2002. p.164.

48

Sobre as discussões e os encaminhamentos acerca da cidadania na Constituição do Império, ver SLEMIAN, Andréa. "Seriam todos cidadãos?"... Op. Cit. Ver também o capítulo 1 da minha dissertação Nem cidadãos, nem brasileiros..., Op. Cit.

49

ASIB. 1826. Tomo II. Rio de Janeiro: Typographia Nacional, 1878. Sessões em 26 e 30/06/1826, p.130; p.156-157.

50

ASIB. Sessão em 26/06/1826..., Op. Cit., p.130. contexto das Cortes portuguesas passam a ser contempladas também na Assembleia Constituinte Brasileira de 1823. Estou me referindo especialmente ao projeto de José Bonifácio de Andrada e Silva, "Apontamentos para a civilização dos índios bravos do Brasil", que é uma versão levemente modificada do texto apresentado em $1821 .{ }^{44} 0$ texto de Bonifácio tornou-se uma referência tanto coeva quanto historiográfica sobre os índios no século XIX, mas isso não significa que fosse a única voz. Ao contrário disso, nas Cortes de Lisboa, o que segue encaminhado para a discussão não é o projeto dele, mas o do coronel Francisco Ricardo Zany, morador do Pará. São levados às Cortes, ainda, mais três projetos sobre os índios. ${ }^{45}$

Na sequência, a respeito das práticas parlamentares brasileiras, observam-se, desde a Comissão de Civilização, Catequese e Colonização da Assembléia Constituinte de 1823, até as Comissões de mesma nomenclatura do Senado e da Câmara gerais a partir de 1826, as tentativas de se obterem informações das diversas partes do Império no que tange à questão indígena, para depois poder legislar sobre o tema. Assim, em 1823, a Comissão de Catequese pede que seja distribuído o projeto de Bonifácio para as províncias, a fim de que pudessem mandar informações sobre os índios de seus territórios, seguindo os princípios desse documento. ${ }^{46}$ Embora o projeto de Constituição elaborado pelos deputados em setembro de 1823 não tenha vigorado, há nele alguns pontos que demonstram a necessidade de se resolver futuramente o problema dos índios no novo Império. Isso porque no projeto constitucional há um breve parágrafo que prevê a criação de um órgão para a catequese dos índios, bem como a emancipação lenta dos africanos. ${ }^{47}$ De qualquer modo, este pálido esboço não é transposto para o texto constitucional que passa a vigorar, a carta outorgada por D. Pedro I em março de 1824. No texto constitucional continuam excluídos os indígenas tanto da participação civil, quanto da participação política, conforme o que é encaminhado no projeto dos constituintes. ${ }^{48}$

Já a respeito das medidas tomadas posteriormente pela Câmara e pelo Senado vê-se a busca de informações específicas das províncias para se pensar num projeto ou numa medida nacional que pudesse contemplar realidades muito díspares, conforme delibera a Comissão de Estatística do Senado em junho de $1826 .{ }^{49}$ Esta Comissão pretende obter dados das províncias a respeito de topografia, clima e geografia, além de dados administrativos e populacionais, relativos, inclusive, ao andamento da civilização dos índios. 0 senador Antônio Gonçalves Gomide lê o seguinte parecer na sessão de 26 de junho, que é aprovado no dia 30 do mesmo mês para ser encaminhado:

Sendo preciso organizar um plano geral para a civilisação dos indios, e devendose proceder sobre o objecto de tanta importancia com a maior circumspeção; é a commissão de parecer que se exija de cada um dos presidentes das respectivas provincias as necessarias, e bem circumstanciadas informações sobre a indole dos mesmos, sobre seus usos, e costumes, bem como sobre suas particulares inclinações, que tenham feito sobre o methodo de os civilisar com maior facilidade, $e_{\text {, finalmen- }}$ te, as proporções, que actualmente haja de terrenos para seus aldeamentos, e, cultura, ouvindo sobre todos estes objectos os respectivos directores, assim como sobre as causas, que têm obstado a civilização dos mencionados indios. ${ }^{50}$

Como resultado desta medida, algumas províncias enviam no ano seguinte as informações pedidas sobre os índios, o que serve para compor 
John Manuel Monteiro analisa as informações mandadas pelas províncias em 1827 em MONTEIRO, John Manuel. Entre o gabinete e o sertão..., Op. Cit. Estes dados provinciais, por sua vez, foram publicados na Revista de Informação Legislativa. Janeiro a março de 1971, p.297-351.

52

CUNHA, Manuela Carneiro da. (org.). Legislação indigenista..., Op. Cit., p.191-199.

53

SILVA, Lígia Osório. Terras devolutas e latifúndio. Efeitos da Lei de 1850. Campinas: Ed. Unicamp 1996.

54

SILVA, José Bonifácio de Andrada e Apontamentos para a civilização dos indios bravos do Imperio do Brazil. In: CUNHA, Manuela Carneiro da (org.). Op. Cit. e COSTA, João Severiano Maciel da (Marquês de Queluz). Memória sobre a necessidade de abolir a introdução dos escravos africanos no Brasil, sobre o modo e condições com que esta abolição se deve fazer e sobre os meios de remediar a falta de braços que ela pode ocasionar. In: ___ et. al. Memórias sobre a escravidão. Rio de Janeiro/ Brasília: Arquivo Nacional/Fundação Petrônio Portella/Ministério da Justiça, 1988, p. 13-59 [1821]

55

0 projeto foi lido em 26/06/1826. Annaes do Parlamento Brazileiro. Câmara dos Srs. Deputados. 1826. Tomo II. Rio de Janeiro: Typographia do Imperial Instituto Artístico, 1874 p.283-285. E foi discutido nas sessões de 15, 18 e 19 de julho. Annaes do Parlamento Brazileiro. Câmara dos Srs. Deputados. 1826. Tomo III. Rio de Janeiro: Typographia do Imperial Instituto Artístico, 1874. p.189-237. um quadro das diferenças étnicas, do desigual peso demográfico destas populações nas regiões, bem como das diversas posturas das autoridades locais, que propõem caminhos que vão do massacre à assimilação. ${ }^{51} \mathrm{De}$ qualquer maneira, apesar da tentativa de se chegar a algum projeto para os índios logo no início da primeira legislatura do Império, nada será proposto como uma diretriz geral para todo o território, pelo menos até 1845, em que se aprovará um decreto nacional, contendo o "Regulamento acerca das missões de catequese e civilização dos índios".52

Acredito que isso tenha se dado porque diversos projetos apresentados numa casa e noutra esbarram em indefinições sobre a posse territorial (em aberto desde a suspensão das doações de sesmarias em $1822^{53}$ ) e ao tipo de mão de obra a se utilizar na instalação de novas atividades. Entram, então, os impasses a respeito da escravidão, ameaçada pelos tratados ingleses pelo fim do tráfico, que colocam possibilidades de substituição dos escravos, seja pela vinda de colonos estrangeiros de origem europeia, seja pelo uso de trabalhadores indígenas. Isso demonstra que a não resolução da questão indígena nas primeiras décadas do Império caminha ao lado da indefinição de ambos os temas a ela subjacentes: as questões de terras e de mão de obra. Assim, durante a construção do Estado nacional brasileiro, cabe definir a apropriação territorial e regulamentar de maneira mais clara aqueles que comporiam a mão de obra nacional, algo que os políticos pré-independência já se preocupam, a exemplo de Bonifácio e João Severiano Maciel da Costa, o Marquês de Queluz. Ambos pensam que a "civilização" e retirada dos índios das matas é um caminho interessante para transformá-los gradualmente em trabalhadores a serviço do Império. ${ }^{54}$ No entanto, a escolha e a consolidação deste trajeto ainda demorariam décadas para serem forjadas, a exemplo do que será a Lei de Terras em 1850, a Lei Eusébio de Queiroz proibindo o tráfico negreiro no mesmo ano, o Regulamento das Missões de Catequese dos Índios de 1845 e os projetos de imigração europeia levados a cabo na segunda metade do século.

Esses impasses podem ser percebidos durante o debate parlamentar a respeito de uma companhia de navegação no Maranhão, que se dá na Câmara federal em julho de 1826 e motiva insolúveis discussões, esbarrando justamente nas indefinições a respeito de terras e mão de obra no Império. Não é possível resolver o que fazer com os índios da região, se trariam trabalhadores estrangeiros ou escravos para operarem ali, como se fariam as doações de terra. Por isso, o projeto, envolvendo temas de tão complexa resolução àquela época, acaba sendo rejeitado devido à impossibilidade de se encaminhar sobre assuntos que o Império ainda não tinha posições definidas e definitivas. ${ }^{55}$

Já durante a Regência, pelo menos no que tange à questão indígena, encaminhamentos e resoluções locais não parecem ser, então, um obstáculo. A respeito da revogação das guerras justas praticadas em São Paulo, o que se percebe na discussão efetuada no Senado, e que na Câmara não tem maiores desdobramentos, é que essa demanda é resolvida de maneira pontual, pois, apesar de impedir que os índios fossem escravizados, não delibera como eles devem ser tratados, nem apresenta um projeto a respeito dessas populações. Mais ainda, deixa de problematizar o tema dentro de uma dimensão nacional, relegando o problema à esfera de São Paulo e, no máximo, estendendo-a a Minas, para onde também haviam sido decretadas guerras justas em 1808. Esse ponto mostra o quanto o foco destes problemas passa se colocar cada vez mais 
Miriam Dolhnikoff discute os impactos das medidas do Ato Adicional na atribuição dos poderes provinciais em DOLHNIKOFF, Miriam. 0 pacto imperial. Origens do federalismo no Brasil. 1ª reimpressão. São Paulo: Globo, 2007.

57

0 projeto de novembro de 1830 é o que Manuela Carneiro da Cunha compila na coletânea de leis do século XIX: 03/11/1830. Resolução do Senado. Abolição da Escravidão dos Indios Selvagens Prisioneiros de Guerra. In: CUNHA (org.). Legislação indigenista..., 0p. Cit., p.134-135.

58

ASIB. 1831. Tomo I. Op. Cit. Sessão em 26/05/1831, p.223. numa esfera provincial, talvez antecipando o que seria o grande aspecto colocado pela Regência. Especialmente após o ato adicional à Constituição, de 1834, o qual, dentre outras medidas, cria as Assembleias Legislativas Provinciais, onde, a partir de então, passam a ter atribuição e orçamento próprio para cuidar da catequese e civilização dos índios. ${ }^{56}$

Ainda que estivesse longe de ser uma proposta relativa ao destino dos índios dentro do Brasil, como será o Regulamento das Missões de 1845 , retomando missionários e diretores como agentes da incorporação destes grupos, esta medida adotada pelo Senado em 1831 simboliza dois movimentos. 0 primeiro de atendimento aos anseios dos moradores da província paulista em suas relações com os índios. A pressão por essa decisão pode ter se dado até pelo fato dos membros da Comissão de Catequese serem dois senadores eleitos por São Paulo (Marquês de São João da Palma e Visconde de Congonhas do Campo), que deviam ter interesses mais diretos no tema.

0 segundo movimento perceptivel é que a resolução de um tema importante, a escravidão dos índios, dá-se de maneira localizada e restrita, como se as questões indígenas não pudessem ou não precisassem ser problematizadas dentro de uma magnitude nacional. Para se visualizar essa postura extremamente focalizada, basta acompanhar o texto desta resolução e sua divulgação. Ela não figura na Coleção das Leis do Império, sendo compilada na coleção sobre a política indigenista do século XIX, organizada por Manuela Carneiro da Cunha, como uma resolução do Senado de 5 de novembro de 1830 que, segundo a pesquisa de Cunha, foi transcrita a partir de uma publicação de Debret. ${ }^{57}$ No entanto, eu encontrei este mesmo texto apenas como um projeto da Comissão de Catequese do Senado do Império, apresentado e transcrito nos Anais do Senado, justamente na sessão de 5 de novembro de 1830.0 texto final, que subiu à sanção da Regência em 1832, após as discussões efetuadas em 1831, tem um conteúdo um pouco diferente da "resolução" transcrita por Cunha, que na verdade é apenas o primeiro projeto sobre as guerras justas contra os índios de São Paulo. 0 que vigora é o segundo projeto, com algumas alterações, tendo sido apresentado no Senado em 26 de maio de 1831, discutido no mês seguinte e aprovado pelo plenário. Desconheço alguma publicação deste texto, além de sua transcrição nos "Anais do Senado do Império de Brasil" em 1831. ${ }^{58}$ No entanto, como o texto final sofreu uma emenda, a versão final deste decreto permanece inédita. Consegui encontrar uma versão manuscrita, na Seção de Documentos Históricos (SEDHI) da Câmara dos Deputados atual, em Brasilia, que transcreverei ao final deste artigo. Antes de chegar ao texto definitivo, vejamos alguns pontos do debate.

A discussão no Senado, iniciada em 11 de novembro de 1830, uma semana depois da apresentação do projeto na tribuna, tem a seguinte defesa de um membro da Comissão de Catequese, Visconde de Congonhas do Campo, representante da província paulista: como os legisladores da nação têm por objetivo o aumento da população do Império, deveriam providenciar para que a medida a respeito de São Paulo fosse extensiva às demais províncias, inclusive Minas Gerais, onde essas leis também são praticadas. No entanto, citando o artigo 81 da Constituição, Congonhas argumenta que são os Conselhos Gerais das Províncias que devem encaminhar projetos relativos às demandas de suas regiões para que sejam contemplados pela Assembleia Legislativa. Portanto, a aprovação deste 
ASIB. 1830. Tomo III. $1^{\text {a }}$ sessão da $2^{\text {a }}$ legislatura (4 de Setembro a 30 de Novembro de 1830). Sessão extraordinária. Rio de Janeiro: 1914, p.389-390. Sessão em 11/11/1830, p.448-449.

60

ASIB. 1831. Tomo I. $2^{\text {a }}$ sessão da $1^{\text {a }}$ Legislatura (7 de Abril a 21 de Junho de 1831). Sessão extraordinária. Rio de Janeiro: 1914. Sessão de 13/05/1831, p.106-107.

61

ASIB. 1831. Tomo I. Op. Cit. Sessão em 13/05/1831, p.108-114.

62

Ibidem, p.114. projeto fica restrita a São Paulo, sendo prudente esperar que as províncias mandem outras propostas que atendam a seus interesses específicos. ${ }^{59}$ Como dito anteriormente, as deliberações a respeito das políticas indígenas neste período indicam o quanto este problema passa a ser encarado como um tema provincial, não cabendo uma lei geral que abarcasse a diversidade das situações dos índios nas várias partes do Brasil. Além do mais, os próprios legisladores e o governo desconhecem o conjunto destas demandas. A partir dessa argumentação, o projeto é aprovado para ser discutido e entra na pauta das sessões do Senado em 13 de maio de 1831.

É justamente na primeira discussão do ano seguinte que o senador Almeida e Albuquerque argumenta que seria vergonhoso aprovar-se uma lei a respeito do tema, e que o mais conveniente seria o governo tomar uma medida administrativa punindo aqueles presidentes de província que permitissem a continuidade das violências contra os índios em suas localidades. É interessante que nessa fala se coloque a ideia de que a guerra justa, como uma prática reeditada por D. João VI no sentido não de propagar a violência, mas de ser um instrumento para conter a "barbaridade" dos indigenas, passe a ser pensada pela ótica inversa. No entanto, o senador Marquês de Inhambupe permite notar que essa posição não é unânime e que, ainda que concordasse sobre o despropósito de se agredirem as "tribos domésticas", afirma que, em relação aos "bugres", que fazem guerras de devastação, com incêndio e "carnagem", não se pode ficar de braços cruzados, então a guerra por parte do Império deve continuar. ${ }^{60}$

Há que se notar ainda que, paralelamente a essa discussão, entre os anos de 1830 e 1831, correm as polêmicas sobre o tráfico negreiro, aprovando-se medidas sobre o fim do comércio de escravos no Império. Ainda que o fim efetivo do tráfico e mesmo a abolição da escravatura serão práticas vigentes num futuro não tão próximo, é interessante pensar que projetos de contatos menos hostis com as populações indígenas, ocorram justamente quando os limites ao acesso à mão de obra africana estão colocados. Isso, inclusive, é apontado pelo senador José Saturnino da Costa, membro da Comissão de Catequese, na sessão de 13 de maio de 1831, ao pôr ambas as leis no mesmo patamar.

\footnotetext{
Com effeito, no momento em que no Brazil se extingue para sempre o trafico, que conduz á escravidão os Africanos com o bem conhecido sacrificio de diminuir consideravelmente os braços a sua Agricultura, preferindo generosamente a gloria de ostentar um ato de humanidade; aos interesses que a olhos visto Ihe cessam, pede a Provincia de S. Paulo que se extirpe do seu seio esse resto de legislação barbara que torna escravos os homens nascidos no nosso solo; neste momento, digo, ha de o Corpo Legislativo negar-se a ir com a vontade daquella provincia? ${ }^{61}$
}

A discussão se estende nesta sessão por mais alguns tópicos, mas a única emenda aprovada é a do senador Marquês de Inhambupe, que altera o artigo $5^{\circ}$, dizendo que "Ficam revogadas todas as disposições em contrário", procurando precaver-se contra outros mecanismos legais que pudessem garantir a guerra aos índios. ${ }^{62}$ No dia 20 de maio, num novo extenso debate, questiona-se a ampliação ou não dessa medida para a província de Minas, onde a guerra justa também vige. No dia 25 próximo, essa dúvida volta à pauta e delibera-se que um novo texto seja escrito, propondo-se uma abrangência geral e que se fale também sobre a forma de sustento dos indios, o que prova que a discussão sobre a temática indígena não se esgota no fim das agressões, mas também sobre o que fazer depois disso. 
63

ASIB. 1831. Tomo I. Op. Cit. Sessão de 20/06/1831, p.404-408.

64

ASIB. 1831. Tomo I. Op. Cit. Sessão em 21/06/1831, p.408-409.

65

ASIB. 1831. Tomo II. $2^{\text {a }}$ sessão da $1^{\text {a }}$ Legislatura (22 de Junho a $1^{\circ}$ de Novembro de 1831. Rio de Janeiro, 1914. Sessão em 21/07/1831, p.170.

66

ASIB. 1831. Tomo II. 0p. Cit. Sessão em 27/10/1831, p.317.

67

ASIB. 1832. Tomo I. $1^{\text {a }}$ sessão da $2^{\text {a legislatura }}$ (27 de Abril a 30 de Junho de 1832). Rio de Janeiro, 1914. Sessão em 05/05/1832, p.11.

68

SEDHI (Seção de Documentos Históricos da Câmara dos Deputados em Brasilia). 1831. Lata 56, maço 3, pasta 1 (Dois projetos sobre índios).
No dia seguinte, 26 de maio, o novo projeto elaborado é lido pelo senador Saturnino. Em 7 de junho tem-se a primeira discussão e a segunda ocorre em 20 do mesmo mês. ${ }^{63}$ Nesta data, se aprova uma emenda do senador Vergueiro aos primeiro e segundo artigos, a respeito das cartas régias serem suspensas somente na parte em que se declara guerra justa, não nos demais itens. Isso porque, para os senadores, os demais itens se referem à civilização dos índios, aspecto que não pode ser menosprezado. Fica aprovada a ressalva "na parte em que se mandou" para os dois primeiros artigos. No dia seguinte, 21 de junho, os demais artigos são lidos e aprovados sem nenhuma discussão, nem emenda. ${ }^{64}$ Exatamente um mês depois, o projeto entra novamente na pauta e, julgando-se discutida a matéria, ele é mandado à Comissão de Redação para que se escrevessem as emendas. ${ }^{65}$ Em 27 de outubro de 1831, informa-se que a Câmara dos deputados recebera o projeto do Senado e o aprova sem alterações, mandando-0 subir à sanção imperial. ${ }^{66}$ Esta será confirmada em 05 de maio de $1832 .{ }^{67}$

0 que se depreende do texto final é que a economia dos artigos e seus conteúdos refletem também a timidez das propostas imperiais. 0 que os senadores parecem ter concluído é que as agressões contra os índios não são o melhor meio de os atraírem à civilização. Portanto, as cartas régias que declaram guerras justas devem ser revogadas. No entanto, somente na parte das guerras justas, não das demais propostas contidas nas cartas. Sobre o que fazer com os indios, os legisladores apenas dizem que fiquem na condição de órfãos, cabendo ao Juiz de Órfãos zelar pelos seus bens e instrução, e ao Juiz de Paz cuidar para que essas medidas sejam cumpridas. Como se vê abaixo, na transcrição do decreto, pouco é dito além disso.

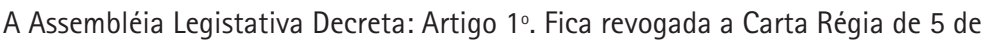
Novembro de 1808, na parte em que mandou declarar a Guerra aos Indios Bugres da Provincia de São Paulo, e determinou que os Prisioneiros fossem obrigados a servir por quinze annos aos Milicianos, ou Moradores, que os apprehendessem. Artigo $2^{\circ}$. Ficão tambem regovadas as Cartas Régias de 13 de Maio, e de 2 de Dezembro de 1808, na parte em que authorisão na Provincia de Minas Geraes a mesma Guerra, e servidão aos Indios Prisioneiros. Artigo $3^{\circ}$. Os Indios tidos até aqui em servidão serão d'ella desonerados. Artigo $4^{\circ}$. Serão considerados como Orfãos e entregues aos respectivos Juizes, para Ihes aplicarem as providencias da Ordenação Livro $1^{\circ}$ Titulo 88. Artigo $5^{\circ}$. Serão socorridos pelo Thesouro do preciso, até que os Juizes de Orfãos os depositem, onde tenham sallarios, ou aprendão officios fabris. Artigo $6^{\circ}$. Os Juizes de Paz nos seus Districtos vigiarão e socorrerão os abusos contra a liberdade dos Indios. Paço do Senado em 27 de Julho de 1831. Bispo Capellão Mór prezidente Visconde de Caethé $1^{\circ}$ secretário (último nome ilegivel). ${ }^{68}$
}

Como essas medidas seriam aplicadas e qual o papel dos índios no Império não seriam enigmas solucionados pelos parlamentares nesta época. 0 quanto os paulistas e os índios seriam afetados por esta medida, é matéria para outro estudo. Mas no momento em que se consegue aprovar essa medida de "liberdade" para os índios do Brasil, diversas partes que compõem o Império, dos índios do sertão paulista aos senadores, de alguma maneira dialogam. 